\title{
Literature, Economics, and a Turn to Content
}

\begin{abstract}
On Economics and Literature: A Comparative and Interdisciplinary Approach, ed. Çinla Akdere and Christine Baron; The Routledge Companion to Literature and Economics, ed. Matt Seybold and Michelle Chihara; Sarah Comyn, Political Economy and the Novel: A Literary History of "Homo Economicus"; Nancy Henry, Women, Literature, and Finance in Victorian Britain: Cultures of Investment; and Gary Saul Morson and Morton Schapiro, Cents and Sensibility: What Economics Can Learn from the Humanities
\end{abstract}

\section{The Great Novels Problem}

Whatever else one might say about the variety of new studies in literature and economics, they cannot be accused of navel-gazing. Each of the new studies reinvigorating this subfield is written with an eye toward the broader world and a sense of the often-limited place of literature within it. Perhaps the most striking fact about reading these studies together is the realization that the depth of the insight is often inversely proportional to the claim for the unique status of literature. At their least effective, these new works produce broad claims for the power of literary thinking to intervene in the economy, or for the power of formalist analysis of literature to reveal new truths about the nature of the economy. In contrast, many of the works find surprising insight in the study of the ordinary representation of economic life.

Notable in this regard is which works of scholarship acknowledge their predecessors; we have, after all, been here before. The New Economic Criticism, an anthology edited by Martha Woodmansee and Mark Osteen, was published in 1999 and expressed a decade of thinking and organization. Linking such scholars as Regenia Gagnier, Elaine Freedgood, and Howard Horwitz, Woodmansee and Osteen sought to recognize and advance an increasingly sophisticated strain of thinking about the relationship between literature and the economy, literary criticism and economics. As they put it in their introduction, for too long literary critics limited their knowledge of overtly economic thought to the works of Karl Marx, ignoring the diversity of thinking in economics and correspondingly limiting the potential for interdisciplinary criticism. The literary tradition had insights beneficial to economists, Woodmansee and Osteen contended, if literary critics were willing to speak their language. Any student of Dostoevsky's Notes 
from the Underground, for instance, would have an understanding of the omnipresence of irrationality that exceeded that of even sophisticated advocates of rational-choice theory (Woodmansee and Osteen 1999: 20).

It is perhaps too strong to say that the New Economic Criticism failed to establish itself as a critical movement, though in their introduction to The Routledge Companion to Literature and Economics Matt Seybold and Michelle Chihara (2018: 6) noted the "paucity of successors" to Woodmansee and Osteen's work. What does seem clear is that the interdisciplinary exchange Woodmansee and Osteen hoped to initiate did not, on the whole, come about. While economics has undergone a series of dramatic shifts in recent years, this has had essentially nothing to do with the scholarship of economically minded literary critics. At the same time, literature scholars - including those surveyed here-generally found it more useful to take some critical distance from the term New Economic Criticism than to sign up under the label.

That has produced some regrettable confusion and duplication. This is particularly prominent in Cents and Sensibility, a polemic in favor of "humanomics" by the literary critic Gary Saul Morson and the economist Morton Schapiro (2017: 150-51), who do not acknowledge Woodmansee and Osteen's work but repeat its point about Notes from the Underground. In the eyes of Morson and Schapiro, literary thinking is a catchall term for the moral concerns and humanistic ways of understanding that economic thinking has traditionally left out. This is at once very specific and very broad: their conception of literature is primarily limited to the realist novels of the second half of the nineteenth century (despite the title, Jane Austen makes only a few appearances), and their conception of literary criticism is largely limited to the act of appreciating the wisdom in such texts in company with students. But the transformation they imagine regarding economists is vast: the humanities and arts are what make for lives "worth living," and the quantitative rigor of economics requires the "empathy, judgment, and wisdom" of the humanities, at least when they are "at their best" (293).

The sense that great novels hold invaluable insight into human behavior is perhaps the most at-hand argument for establishing literature's value for those outside the field of literary study. But familiar as this claim might be, it fails to identify what exactly the study of literature - as opposed to reading the most canonical of novels - offers thinkers in the field of economics. In one instance, Morson and Schapiro (2017: 285) give "self-deception" as an example of a "genuine irrationality" that novels are better equipped than economic theory to explain 
because, they conclude, the latter is fundamentally tied to a "rationalist perspective." This claim, which is emblematic of their overall approach to literature and economics, raises several questions. For one thing, what they cite as a fundamental and decisive problem in the theory of agency is in fact a fairly old issue, the theoretical treatment of which dates back at least to Jean-Paul Sartre's 1943 treatise Being and Nothingness. For another, it is tough to see how this generates an argument for the importance of studying literature as such. It seems quite plausible that the great novelists of the literary tradition have indeed understood the nature of self-deception and the structure of irrational agency. But one would think that this is not primarily because they were writing literary texts but because they were subtle and creative thinkers who chose literature as the outlet for their thinking. Maybe economists ought to read George Eliot and Leo Tolstoy, but this argument implies that they ought to do so for the same reason they should read the works of economist Daniel Kahneman. Is there any reason economists ought to care about literature as such, that is, over and above the reasons a particularly insightful literary writer might be worth reading?

The ominous-sounding implications of the phrase the humanities at their best are not an accident, by the way: Morson and Schapiro think the humanities in recent generations have most definitely not been at their best. Partly that is because of the pernicious influence of poststructuralism, which has convinced humanists that there is no intrinsic value or moral worth in the objects they study. But it is also because humanists tend to opine on economic matters with insufficient rigor, unprepared to acknowledge a genuine need for effective ways of dividing up limited resources (259-60). The odd conjunction of critiques here-humanists being chided for dismissing at once moral values and the logic of the market - is worth noting, not least because a commitment to traditional moral values and to the importance of the free market is a defining feature of the contemporary Republican Party. That fact no doubt helps frame Morson's 2017 keynote for the Heritage Foundation, subsequently published as "Pray for Chekhov: Or What Russian Literature Can Teach Conservatives."

But having noted that conjunction, let us return to the claim about the supposedly insufficient economic knowledge of literary critics and simply say that this claim is inaccurate. Moreover, it makes the omission of a sustained treatment of Woodmansee and Osteen's collection-not to mention the many other monographs published in this area between 1999 and today-more damning. In fact, it is precisely because literary critics are so informed about the market, and particu- 
larly the various markets in cultural products, that they have questioned traditional notions of artistic value. That was one of the points Elizabeth Hewitt (2009) made in her review essay "The Vexed Story of Economic Criticism": it has seemed to many writers who have thought about the problem that taking markets seriously means generally disregarding the aesthetic, since regarding the literary text as a commodity was at odds with the view that it was an instance of the autonomous aesthetic realm. So, far from comparing their own attempt to integrate the two ways of viewing the world to other work in this field, Morson and Schapiro fail even to recognize that it's a problem.

\section{Dominant Critical Threads in Economics and Literature}

Other research in the field has done better in this regard. In The New Economic Criticism, Woodmansee and Osteen (1999: 29) laid out what they saw as the four main threads of criticism at the intersection of economics and literature: (a) production: analyses of the social, cultural, and economic context in which a literary text is produced; (b) circulation: analyses of the "internal circulation" of words and figures within literary texts, possibly analogous to the economic circulation of goods, services, and/or capital (30); (c) consumption: accounts of the "external circulation and consumption" of such texts as they are alternatively promoted, sold, and canonized (31); and (d) "metatheoretical" research that interrogates the idea of a meaningful connection between literary criticism and economics, asking, for instance, whether the metaphor of the "economy" is the best way to describe the circulation of words (32). Several things are striking about this list today, twenty years after it was written. First is how conscious it is of the problem Morson and Schapiro ignore: that the literary work is simultaneously a work of art and a commodity. But second is how much recent work has expanded on the categories Woodmansee and Osteen identified.

Certainly, there are some individual pieces that conform to these critical threads. Richard Godden's "Labor without Value, Language at a Price: Toward a Narrative Poetics for the Financial Turn" in The Routledge Companion to Literature and Economics falls within Woodmansee and Osteen's (1999) "circulation" category, as he argues that both literary signifiers and "monetary terms" are "products of social relations in process" (Seybold and Chihara 2018: 60). Mary McAleer Balkun's "The Print Revolution and Paper Money" in the same volume arguably falls into their "production" category, seeing the development of the printing industry in America as intertwining the development of paper money and fictional narrative. And Gilles 
Jacoud's "Literature and Political Economy" in Economics and Literature (Akdere and Baron 2018) recalls their third category, "consumption," in its comparative study of contemporary French political theorists, Henri de Saint-Simon and Jean-Baptiste Say, and their use of epistolary writing as a means for gathering a wide readership.

But it is striking how rarely this group of critics has found the economics underlying the production or reception of literary texts to be helpful in thinking about the relationship between economics and literature more generally. Instead they are deeply interested in the representation of economic life in various dimensions and in varying times and places. That emphasis on historical specificity is an overt justification for many of the pieces, most obviously Sarah Comyn's Political Economy and the Novel: A Literary History of "Homo Economicus." But an underlying justification is apparent as well: the turn to history in literature and economics has also been, we submit, a turn to content. Such a category is perhaps too humble to justify a field, which may explain why Woodmansee and Osteen (1999) did not bother to include it in their list. Yet this body of scholarship has found it a surprisingly rich avenue of exploration. Indeed, it seems possible that this was part of the reason the New Economic Criticism failed to secure a hold: it turned too quickly to form and ignored the possibilities that lie in studying literary content.

The essays in Akdere and Baron's Economics and Literature provide ample case studies. Drawn from talks at the 2013 conference on "Literary Representation and Economic Theories," the chapters all reiterate the usefulness of putting scholars of literature and economics into closer connection so that, despite ostensible differences, together they can better account for the world of human behavior. At the same time, these authors labor under an assumption that is everywhere apparent if unstated in the texts themselves: although literature and economics both offer social insight, the latter enjoys a much more prominent place in public debates and on university campuses. Like much of the work in the area of economics and literature, the collection is less interested in justifying the value of economics for literary scholars than in affirming a role for literature to play in economic thought and scholarship. After all, the editors remind us, literature since the Middle Ages has "portrayed the economic world, in poetry, drama, stories, novels" (Akdere and Baron 2018: 1). But the main area of concern for Economics and Literature is, despite its title, not literature per se but the novel. The novel's effectiveness in this area, the editors continue, draws from its consideration of character: by characters striking 
it rich, going bankrupt, or going to Wall Street, novels reveal to a large audience of readers what otherwise would be seen only by a relative few. In short, novels provide "testimony" or "evidence" about the societies portrayed (2).

Elsewhere this critical approach is often limited to analyzing how novels dramatize concepts in economics, but most of the critics considered here find literary texts doing much more than illustration. For example, Bruna Ingrao's contribution to Economics and Literature uses a common approach, reading novelists alongside contemporary economists. But rather than posing economics as the privileged frame for understanding the social setting in an novel, Ingrao treats economics and literature as cothinkers in addressing a particularly heated issue in the financial world of the late nineteenth century: the mismanagement of money in joint-stock banks before regulation in 1879 (Akdere and Baron 2018: 29). Comparing famous representations of fraudulent financiers - like Anthony Trollope's Augustus Melmotte and Charles Dickens's Mr. Merdle_-alongside economic thinkers like John Stuart Mill and Alfred Marshall, Ingrao shows how a vocabulary for and metaphoric language about the figure of the speculator was shared across genres.

But while Ingrao considers the content of writers like Mill and Dickens together, others in the collection pose a sharper distinction between literature and economics. For example, Sarah Key's "Gertrude Stein and Money" revisits a topic that has long been at the intersection of economics and literature: money or currency as symbols of value. Marc Shell's contribution exemplifies this approach, stating that currency and financial markets both "involve the ground of aesthetic experience, and the same medium that confers belief in fiduciary money (bank notes) and in scriptural money . . . also seems to confer it in art" (Woodmansee and Osteen 1999: 44). Key's account of Stein adds to this scholarship by drawing together two contemporary and, Key argues, related events: the fiscal Panic of 1907 and Stein's drafting of her novella Three Lives. According to Key (Akdere and Baron 2018: 133), Stein observed the events of the panic and "was inspired to begin manipulating form and content in ways that mirrored monetary instability." The aesthetic innovations for the modernist poet were "like paper money" inasmuch as each "stands in" for the world outside the thing itself (133). An example of the internal circulation thread that Woodmansee and Osteen (1999) describe, Key's chapter interestingly sets its sights on the figurative transfer between literary works and finance. But while such claims appeal to literary 
critics looking for ways to invigorate literature, it is likely to be unconvincing to readers outside the field who might be expecting an account of Stein's direct interest in and explicit consideration of either the events of 1907 in particular or economic theory more generally. Economics and Literature thus ultimately conveys the strengths and shortcomings of its interdisciplinary field of study: its points are most persuasive when it eschews familiar accounts of literary form and instead treats literary and economic sources together as advancing historically specific ideas about economic life.

For its part, The Routledge Companion to Literature and Economics displays a variety of attitudes toward the historicity of literary texts. Those arguments are developed in an impressive display of interdisciplinary scholarship: in addition to their creative and informed interventions in debates in literary studies, the contributors demonstrate familiarity not merely with the major figures of economic thought but also with the extensive interpretive traditions of figures like John Maynard Keynes and Friedrich Hayek. The structure of The Routledge Companion reflects its variety, dividing its thirty-seven contributions into four sections: two historical and two theoretical. The first section offers four brief histories of traditions of literary-critical ways of thinking about the economy, and the second surveys traditional periods of literary history, from medieval Europe to the present. The third and largest section of the book turns to economic concepts or principles, ranging from corporate space to neoliberalism, while the final section is a methodologically diverse group of chapters on economics and contemporary culture, from an analysis of the media rhetoric surrounding the AOL-Time Warner merger to an argument about the political quietism of the podcast Serial. But the distinctions are, of course, a little artificial: many of the essays on economic principles make historically specific arguments, as in Eleanor Courtemanche's tracing of the nineteenth-century literary response to "classical economics" or Imre Szeman's contribution to the analysis of "petrocultures" (Seybold and Chihara 2018: 188, 227).

The variety of the work and quality of the scholarship mean that the collected chapters defy easy summary and comparison; only a few fall clearly in the categories outlined by Woodmansee and Osteen (1999) in The New Economic Criticism. And there is a welcome variation in the kinds of literary texts considered: although realist novels still play a significant role, there are analyses of poetry, the musical Hamilton, and the movie Ghostbusters; a John Smith pamphlet from the Virginia Colony; and a wide variety of genres of fiction, including 
speculative and science fiction and the gothic novel. The editors of The Routledge Companion to Literature and Economics sensibly do not try to summarize this range in their introduction, limiting themselves to observing its differences from New Economic Criticism and the importance of new finance studies. In light of that variety, perhaps some statistics are the most useful way to describe the volume. Thirtyfour of the thirty-seven chapters include an economist in their works cited, while twenty-seven include a reference to a specific event for which the date is given (not including the publication of a book). Twenty-five chapters include a quotation from a literary text; four chapters do not mention literature at all. Perhaps the most interesting variation involves whether an author treats the literary as a semireflective or unreflective symptom of the economy or sees literature as aware of and reflecting critically on the economy and economic thought. Opinions will differ, but in our estimation nineteen of the chapters are the first category, and fourteen are the second (omitting, of course, the four chapters that do not mention literature). Authors in the first category are inclined to show how the works and genres they considered "imitated" or were "shaped by" the economies in which they occurred, while authors in the second category write of how literature "stages" the interplay of economic forces or "exposes" truths about the economy (Seybold and Chihara 2018: 410, 142, 353, 176).

Perhaps the clearest demonstration of this tension is between the collection's contributions by Alden Sajor Marte-Wood and Christopher Newfield. Marte-Wood goes so far as to historicize not merely the literary but literary criticism, up to and including the economic literary criticism in which he participated: "Economistic literary criticism therefore emerges - both as possibility and necessary - as a historically specific mode of perception capable of seeing literature produced during the contemporary moment of capital's globalized 'permanent reproductive crisis" (Seybold and Chihara 2018: 200). Leaving to one side questions about how exactly one might demonstrate that any school of literary criticism is a "necessary" development, it is a striking contrast to Newfield's argument, which offers Jennifer Egan's "wonderful novel" A Visit from the Goon Squad as an example of "literary knowledge of economy," an essential ingredient in his view for building the future world (23). Certainly the arguments are different, but the attitudinal contrast between Newfield and Marte-Wood is striking, too: Newfield's closing question, "What would it mean to think and act as though literature were in power?" (25), reverses the methodological premises and scholarly attitudes of many of his historicist compatriots. 
Sarah Comyn's Political Economy and the Novel too is troubled by the question of the relationship between history and the literary. Rather than looking at the impact of specific events, Comyn looks more broadly at comparative patterns of thought. The monograph forms part of the new series Palgrave Studies in Literature, Culture, and Economics; the series introduction states that presentist bias forms a major problem within economics and that the historical emphasis of the series will serve as a counterweight to this tendency. Comyn's book fits squarely within that mission, surveying roughly two centuries of British fiction by pairing a novelist with a contemporaneous economist, explaining how the novelist critiques, challenges, or extends the economist's view. Thus, she pairs Adam Smith with Henry Fielding, David Ricardo with Jane Austen, J. S. Mill with Charles Dickens, John Maynard Keynes with Virginia Woolf, Friedrich Hayek with Ayn Rand, and last, Joseph Schumpeter and a variety of other thinkers with Don DeLillo. One interesting feature of the book is how the relationship between economist and author changes from chapter to chapter: Fielding disagrees with the simplified Smith of neoliberal theory but agrees with the real Smith, who insisted on situating economic motives within the realm of moral philosophy and the broader sphere of reasons. In contrast, Rand sees a truth about neoliberalism that Hayek does not: that it is inadequate if taken as only a theory and political economy and needs to be understood as a theory of morality and personal fulfillment as well.

Dealing with such a range of writers is certainly impressive, and Comyn brings admirable clarity to the task. But an odd fact about her argument is that it is not actually a history of homo economicus. Such a history would certainly be worth doing: what does it actually mean to maximize one's interests, and how have people over the last two hundred years attempted to explain and represent that? But what Comyn offers instead is really a history of critiques of homo economicus in Anglophone fiction. At one point in the Dickens chapter, for instance, she reads a description of a character as aligning with Marx's theory of commodity fetishism. Of course, this may be accurate, but at this point the argument has gotten pretty far afield from the psychological theory of agency in the idea of homo economicus. The argument also often depends on granting novelists more interpretive charity than the economists receive. Thus, in the Rand chapter, Comyn (2018: 194) admits that actually Hayek thought neoliberalism was a moral theory too, writing that Hayek was "clearly trying to bring a normative code back into the economic discourse." What was an initially very clear claim distinguishing Rand from Hayek becomes correspondingly much less straightforward—-the difference between 
the two writers turns out to be not philosophical but, rather, attitudinal. Hayek's version of homo economicus is "hesitant, measured, and a traditionalist," while Rand's is "divisive" and "radically uncompromising" (197). So it is not clear that the distinction between Rand and Hayek is as significant as it first appeared to be: these are two writers who basically agree with each other, and it begins to seem like Comyn is emphasizing the literary author not because of the importance of the intellectual contributions but because this is a monograph in literary studies.

In that light it is revealing to contrast Comyn's book in particular with Nancy Henry's (2016) Women, Literature, and Finance in Victorian Britain. Henry is much more of a historian and much less interested in economic theory, and the argument is to some extent less ambitious. There is no argument that the authors she considers merit special attention as innovative economic thinkers or as individual turning points in the history of economic agency. But perhaps because of these factors, it is all the more successful. The umbrella claim disputes the notion that there is a sharp distinction between men's spheres and women's spheres in Victorian public life, as famously argued by Leonore Davidoff and Catherine Hall (1987) in Family Fortunes: Men and Women of the English Middle Class, 1780-1850. Henry argues persuasively that this distinction does not account for women's behaviors in investing. When women were treated as investors, there were fewer barriers to their activity: they could vote in shareholder meetings and hold positions on corporate boards.

Moreover, Henry argues, that fact changed how women were presented and how female authors thought about finance capitalism. To male authors like Anthony Trollope and George Gissing, finance was an unequivocal evil, a symptom of how things had gone wrong and the unnecessary distances that had grown up between worker and consumer. To female authors like Elizabeth Gaskell and Margaret Oliphant, however, the problem was significantly more nuanced: as Henry shows, they tended to have more respect for investing behavior because they saw in it an opportunity for female agency not available elsewhere, and particularly not in the male-dominated professions. That change in attitudes had some ramifying effects: Henry contributes to the rediscovery of an author named Charlotte Riddell, apparently known to the Victorians as the "novelist of the city," who wrote several novels about the evils of limited liability-presumably because it made it somewhat easier to defraud shareholders. Yet in Henry's portrayal these representations had moral nuances. One in particular Henry returns to several times is the fact that Liverpool was a center of 
the slave trade and a symbol for the connection between slavery and finance, and in her argument this was a fact the novelists were well aware of. If they did not quite believe in "ethical investing," she concludes, they still did significant thinking about whether money could be morally tainted (Henry 2018: 19).

Henry's book proceeds by uncovering an author's financial life and then linking it to the representation of investment behavior in her work. Particularly interesting are the accounts of authors who went through bankruptcy, like Riddell and Oliphant, and who had to rescue their debt-accruing husbands and children with money from their writing. But many of the incidental details are compelling as well: apparently George Eliot deeply enjoyed attending to her investments and tracing her involvement with the details of her money at work. There are some limitations to the study. The readings, for instance, are generally interested in explaining how the works of an individual author confirm the overall thesis about the financial lives of women, as opposed to noting variations on it. That makes sense, but one could imagine the book proceeding in a different thematic fashion, tracing different ways of thinking about the ethics of investing differences via how authors thought about their investments. But more significant is the book's perhaps unnecessary modesty about its method, which is quietly innovative. Rather than one of the many variants of formalist historicism that have dominated recent work in literary criticism, this is old-fashioned thematic history: Henry is more or less straightforwardly reading for the content and using that content to describe what it was like to be a female investor at a particular place and time. Thus, the new-old method of the book implicitly reflects a deep objection to some prominent ways of doing economic criticism.

\section{Conclusion: Beyond War and Peace}

As we have stressed, work in economics and literature best fulfills its interdisciplinary potential when it treats both fields together as sources that generate important ideas about society and economics. It is worth elaborating on this claim, lest it retread old ground about the value of literature in this dynamic. To treat economics and literature as coproducers of knowledge does not advocate for a one-size-fits-all approach to how literary works are crafted or the knowledge they contain. War and Peace might offer ideas relevant to biologists and conservative Republicans alike, but at a certain point the repeated references to a small cadre of canonical works say less about the books themselves than about the critic's attachment to them. Instead, to treat literature 
as coequal with economics is to deemphasize the aesthetic nature of the literary, treating such texts as equally important ways of grasping social life. Such an approach is not even really new; the separation of these two disciplines into distinct fields of knowledge is, after all, a relatively recent phenomenon. Writers in the nineteenth century such as Émile Zola and Henry James understood their work as helping theorize the social, especially as it relates to the perception of class, social mores, and taste, and such works were not always sharply distinguished from the burgeoning social sciences.

By way of conclusion, it is worth admitting that to treat literature in this way calls us to expand our sense of what texts count as serious or praiseworthy. Amitav Ghosh (2016: 23) makes a similar plea in The Great Derangement, noting that serious literary fiction has largely failed to adequately confront the real and growing problem of climate change. As improbable events are becoming more realistic, so to speak, the failures of the realist novel to document them become more salient and troubling, and taking the social seriously requires breaking realism's monopoly on the production and consumption of novels as producers of ideas about the world. While Ghosh is writing in respect to climate phenomena, his understanding of fiction as something that produces real social knowledge undoubtedly applies to scholarship in economics and literature. What might the field look like if it were to topple, or at least more thoroughly scrutinize, the reception of the realist novel as the primary literary form where social knowledge is produced and disseminated? In that light we welcome the generic diversity of the texts considered in The Routledge Companion to Literature and Economics, and we hope that Morson and Schapiro, authors of Cents and Sensibility, consider such a range of literature-Jane Austen, sure, but also Dave Eggers and Lin-Manuel Miranda-in their continued pursuit of a humanomics.

\section{Works Cited}

Akdere, Çinla, and Christine Baron, eds. 2018. Economics and Literature: A Comparative and Interdisciplinary Approach. New York: Routledge.

Comyn, Sarah. 2018. Political Economy and the Novel: A Literary History of "Homo Economicus."Cham, Switzerland: Palgrave Macmillan.

Davidoff, Leonore, and Catherine Hall. 1987. Family Fortunes: Men and Women of the English Middle Class, 1780-1850. Chicago: University of Chicago Press.

Ghosh, Amitav. 2016. The Great Derangement: Climate Change and the Unthinkable. Chicago: University of Chicago Press.

Henry, Nancy. 2018. Women, Literature, and Finance in Victorian Britain: Cultures of Investment. Cham, Switzerland: Palgrave Macmillan. 
Hewitt, Elizabeth. 2009. “The Vexed Story of Economic Criticism.” American Literary History 21, no. 3: 618-32.

Morson, Gary Saul. 2017. "Pray for Chekhov: Or What Russian Literature Can Teach Conservatives.” Heritage Foundation, March 28. www.heritage.org /conservatism/report/pray-chekhov-or-what-russian-literature-can-teach -conservatives.

Morson, Gary Saul, and Morton Owen Schapiro. 2017. Cents and Sensibility: What Economics Can Learn from the Humanities. Princeton, NJ: Princeton University Press.

Seybold, Matt, and Michelle Chihara, eds. 2018. The Routledge Companion to Literature and Economics. London: Routledge.

Woodmansee, Martha, and Mark Osteen, eds. 1999. The New Economic Criticism: Studies at the Intersection of Literature and Economics. London: Routledge. 